\title{
Myriam Dufour-Maître, La clémence et la grâce. Étude de "Cinna" et de "Polyeucte" de Pierre Corneille
}

\section{Laura Rescia}

\section{(2) OpenEdition}

1 Journals

\section{Edizione digitale}

URL: http://journals.openedition.org/studifrancesi/1325

DOI: $10.4000 /$ studifrancesi. 1325

ISSN: 2421-5856

\section{Editore}

Rosenberg \& Sellier

\section{Edizione cartacea}

Data di pubblicazione: 1 décembre 2015

Paginazione: 589

ISSN: 0039-2944

\section{Notizia bibliografica digitale}

Laura Rescia, «Myriam Dufour-Maître, La clémence et la grâce. Étude de "Cinna" et de "Polyeucte" de

Pierre Corneille», Studi Francesi [Online], 177 (LIX | III) | 2015, online dal 01 décembre 2015, consultato il 06 janvier 2021. URL: http://journals.openedition.org/studifrancesi/1325 ; DOI: https://doi.org/

10.4000/studifrancesi. 1325

Questo documento è stato generato automaticamente il 6 janvier 2021.

\section{(c) (1)}

Studi Francesi è distribuita con Licenza Creative Commons Attribuzione - Non commerciale - Non opere derivate 4.0 Internazionale. 


\title{
Myriam Dufour-Maître, La clémence et la grâce. Étude de "Cinna" et de "Polyeucte" de Pierre Corneille
}

\author{
Laura Rescia
}

\section{NOTIZIA}

MYRIAM DUFOUR-MAÎTRE, La clémence et la grâce. Étude de "Cinna" et de "Polyeucte" de Pierre Corneille, Presses universitaires de Rouen et du Havre, 2014, pp. 191.

1 Questo manuale, uscito a seguito dell'inserimento delle due tragedie corneliane nel programma dell'agrégation del 2015, si propone come strumento di studio agile ma completo e aggiornato delle due pièces, alla luce delle più recenti acquisizioni della critica contemporanea. Prendendo avvio dalla messa in discussione del mito dell'eroe in Corneille, questione centrale affrontata nel primo capitolo, il percorso di lettura proposto dall'A. si articola su altri sei: il secondo orientato sulla drammaturgia delle due tragedie, sia negli aspetti materiali della rappresentazione teatrale che nella genetica del testo; il terzo è impostato sulla ricerca dei congegni retorici dei due testi, con una particolare attenzione alla retorica "à double fond"; il quarto è interamente dedicato al problema della spettacolarizzazione degli eventi su scena, e al complesso sistema di funzionamento di queste due tragedie, tra ipotiposi, evocazione dell'immagine attraverso la sollecitazione della fantasia, alla ricerca di questo fondamentale aspetto della poetica corneliana; il quinto affronta il problema della concezione del tempo, inteso nelle sue multiple accezioni di tempo finzionale, drammaturgico, teatrale e intimo (o tempo dello spettatore); il sesto si concentra sulla dimensione ideologica delle due pièces, proponendo un parziale rovesciamento dell'interpretazione canonica, attraverso un'indicazione di lettura che cerca in Polyeucte la tragedia politica e in Cinna quella cristiana; il settimo infine si sofferma sulla ricezione delle pièces, sugli effetti voluti dal drammaturgo per i suoi spettatori, inscrivendo sotto l'egida della douceur (la mitezza, così come descritta nel celebre 
saggio di Norberto Bobbio, qui opportunamente citato) non solo la visione dei fatti presentati dal drammaturgo nelle due tragedie, ma la sua stessa postura autoriale. Lontano da uno stoicismo estremo, Corneille sembra voler indicare al suo pubblico la duplice via, della clemenza e della grazia, attraverso la quale giungere al sublime. In appendice a questo percorso, si troverà una breve antologia critica, che da Péguy attraverso Bénichou, Rousset, Fumaroli, conduce a Merlin-Kajman e Kintzler. Una bibliografia volutamente succinta indica i testi imprescindibili (saggi e articoli) per inquadrare il problema critico su Corneille oltre che sulle due tragedie al centro dell'attenzione dell'A. Riuscendo ad evitare l'eccessiva eterogeneità che potrebbe derivarne, l'A. assume e armonizza diverse metodologie e numerosi contributi di tutti i maggiori critici corneliani, che vengono opportunamente e ampiamente citati in nota. Questo saggio è particolarmente apprezzabile per chiarezza, completezza, nonché per la ricchezza di citazioni delle pièces esaminate, che occupano una parte ampia nell'economia delle pagine; le aperture a letture critiche anche estranee allo specifico corneliano (Lacan, Bobbio, Agamben) gli conferiscono un respiro che spesso manca ai manuali contemporanei, rendendolo sicuramente consigliabile per la didattica universitaria. 